\title{
Universidad y Ciencia en América Latina*
}

Referirse a la Investigación y Ciencia (I \& C) en el mundo actual es reflexionar sobre las bases mismas de sustentación de nuestro desarrollo, sin entrar a discutir todavía, a qué modelo de desarrollo aspiramos. La I \& C no sólo la percibimos a través de sus productos o aplicaciones tecnológicas, en lo que llamamos "sociedad industrial" o "sociedad moderna" aludiendo a la racionalidad que marca a la humanidad desde hace cuatro o cinco siglos. La Ciencia ha resultado ser un paradigma y sustento de toda idea que se pretenda legítima e incontrastable. Hoy representa el sentido común de los sectores ilustrados que dirigen la sociedad $y$ ha servido para una suerte de legitimación de la autoridad y la verdad. Sin embargo, mas allá del conjunto de disciplinas y saberes particulares que la ciencia ha desarrollado, ha sido la racionalidad científica, como conjunto, la que sostiene esta perspectiva.

En el presente asistimos a una expansión acelerada en el ámbito mundial de la ciencia y de la tecnología; sin embargo esto no significa que exista un desarrollo homogéneo y equitativo. Si consideramos algunos datos, al año 1992 los gastos totales en investigación y desarrollo, en el mundo entero, eran de 25000 millones de dólares.
El 83\% corresponde al triángulo Europa, Estados y Japón; otros países industrializados de Asia, el 9,5\% y los países de la ex URSS el 4\%. Ciertamente América Latina aparece relegada a los últimos lugares, destacándose que representa el $1 \%$ de los gastos globales y contribuye con 1,4\% de la producción científica. África aún está en peores condiciones con $0,5 \%$ de los gastos mundiales y 1,2\% de contribución a la producción científica. Preferimos hacer la comparación por zonas geográficas y no por países pues el resultado puede ser aún más desolador.

El abismo es creciente. Así, de la mano de las nuevas tecnologías, han empezado a surgir, también, nuevas estrategias industriales apoyadas en las llamadas tecnologías críticas o tecnologías claves. La adecuada articulación en el desarrollo de componentes electrónicos y de telecomunicaciones, las transformaciones producidas por las nuevas tecnologías de información en los sistemas de producción y las expectativas derivadas de los adelantos en biotecnología han hecho emerger tecnologías capaces de orientar y promover el desarrollo de grandes sectores industriales en los campos de la informática y componentes de microelectrónica, nuevos materiales,

\footnotetext{
* Ponencia presentada en el Seminário Internacional "Universidade e Ciência na América Latina: a Ciência para o século XXI”, Porto Alegre, Brasil, novembro de 1999.

${ }^{1}$ Rector de la Universidad de Santiago de Chile
}

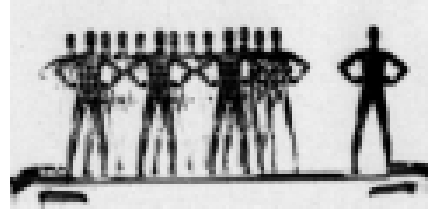


ingeniería genética etc. En América Latina si aún no superamos las etapas previas, estaremos aún más alejados de estas nuevas estrategias de desarrollo que se implementan en los países del primer mundo. Esto también ha conducido a una suerte de reparto del mercado tecnológico cuando se constata que, por ejemplo, la Unión Europea controla el $30 \%$ de los productos farmacéuticos, $25 \%$ de la aeronáutica, el $16,7 \%$ de la industria química y el $8,7 \%$ de la electrónica. Por su parte, Japón es dominante en la electrónica $(23,2 \%)$ y en el transporte terrestre (21,8\%). Estados Unidos domina prácticamente el $50 \%$ del mercado de la aeronáutica y el $20 \%$ de la electrónica y material informático.

Esta realidad impacta de manera dramática en nuestra región. Las desigualdades se incrementan, claro está no sólo por la insuficiente producción científicotecnológica, sino por la incapacidad de ciertas políticas económicas para dar lugar a mayor equidad y bienestar. Las decisiones económicas son cada vez más ajenas al hombre común pues se adoptan en los grandes centros de poder de los cuales estamos ausentes. Nuestro país, Chile, es uno de los principales países exportadores mundiales de cobre, pero el precio no se fija dentro de nuestras fronteras sino en la Bolsa de Metales de Londres. Ciertamente este no es un hecho reciente, pero esa es la tendencia, las decisiones están donde quienes las adoptan, muchas veces, ni siquiera conocen el lugar de donde proviene aquello que venden. América Latina se enfrenta al dilema de acoplarse al tren de la globalizacion como se concibe desde el norte o bien intentar desarrollar capacidad propia. La actual situación, nos tiende a relegar a la monoproduccion o como mucho a la exportación de nuestras materias primas más abundantes y competitivas en los mercados internacionales. Pero esta competencia más allá de favorecernos temporalmente fragiliza nuestras economías y las hace muy vulnerables y dependientes a los vaivenes de los precios que de manera cíclica afectan a la economía mundial. El desafío de la diversificación en la oferta de productos es un objetivo a mediano plazo que es urgente lograr, productos con mayor elaboración para lo cual se requiere de conocimiento especializado.

El conocimiento y la información ofrecen posibilidades ilimitadas que deben desarrollarse de manera que la cultura no sólo vaya en beneficio de aquellos que controlan los mercados. La tarea es buscar las estrategias adecuadas a fin de que la redistribución de la riqueza también signifique una redistribución del conocimiento.

La globalización no puede constituirse en una nueva forma de exclusión y sometimiento, pensamos que el proceso es ineludible y nuestra tarea es luchar por abrirnos espacios donde se considere nuestra especificidad, donde la modernidad no sea una construcción desde afuera sino una necesidad consciente y coherente con las carencias que hay que superar. Ciertamente que la tarea es difícil cuando la enfrentamos desde las perspectivas individual y nacional. Hay que avanzar en el proceso de integración a nivel continental y regional. La integracion no debe ser un acto declarativo, es una necesidad que debe permear todo nuestro quehacer. La voluntad debe materializarse en diseñar sistemas educacionales para estos nuevos tiempos. Las universidades y los Centros de Investigación deben construir su quehacer a partir del diagnóstico de los problemas y carencias que debemos superar. A través de la integración, la globalidad puede adquirir una dimensión más solidaria $y$ cooperativa. Debemos avanzar en el aprovechamiento de las complementariedades. Los países industrializados destinan prácticamente la totalidad de sus recursos de investigación (98\%) a resolver sus prioridades. Esta es una verdad que debiera ser un fuerte estímulo cuando se trata de diseñar las políticas de investigación en los países de América Latina. 
El desafío es generar una cultura donde la integración y cooperación transversalicen todas las iniciativas y proyectos. Los sistemas educacionales y en particular la educación superior, tienen la misión de desarrollar curriculum a través de la síntesis del saber en un contexto de diversidad y cambio estrechamente vinculado a la integración y cooperación.

La pregunta que surge es ¿Cuál debería ser la estrategia de nuestro países, de América Latina, para aprovechar esta gigantesca disponibilidad de conocimiento en ciencia $y$ tecnología? ¿Cómo hacer de este conocimiento un factor de transformación y progreso para nuestros pueblos?. Es imprescindible desarrollar una visión estratégica que estimule la investigación fundamental y que a la vez permita la aplicación y desarrollo de tecnologías adecuadas al grado de desarrollo que vivimos.

Ya observamos, que frente a la globalización existe un impulso creciente a la integración de comunidades regionales y continentales (Europa, Asia, América del Norte, son algunos ejemplos). El solo hecho de la integración no es por sí mismo señal de éxito. Esta debe ir acompañada de modelos de desarrollo alternativo que privilegien la solidaridad y cooperación para evitar una agudización de las desigualdades frente a poderosos modelos de desarrollo que exhiben los países industrializados. En este proceso, la universidad, en América Latina, puede desempeñar un rol clave. Existe una cierta forma de experiencia desde hace muchos años donde las universidades latinoamericanas han experimentado contactos; pero solamente a partir de la década de los noventa y a partir de diversas reuniones para acordar formas más concretas de intercambio, es cuando las nuevas formas de colaboración empiezan a materializarse. La paulatina formación de redes de distinto carácter, algunas con énfasis en ciertas disciplinas, hace que las universidades empiecen a configurar una nueva concepción de la colaboración.

\section{¿Qué significa hacer Ciencia en América} Latina?

Quizás esta pregunta puede ser un poco obvia. No obstante creemos que tiene plena validez en el contexto regional. La realidad actual se sostiene en una creciente interdependencia y nuestro futuro está estrechamente ligado a la comprensión de los fenómenos y sus alcances. Ya son muy pocos quienes no reconocen que la supervivencia de las formas de vida que conocemos puede estar en serio riesgo de existencia de continuar con las actuales formas de explotación del planeta. La sociedad debe tener conciencia del uso adecuado del conocimiento. Si bien la ciencia ha sido un factor fundamental en el desarrollo humano, al permitir mayores expectativas de vida, aumento de la producción agrícola, fuerte desarrollo tecnológico que ha permitido que la fuerza de trabajo humana sea reemplazada por la de las máquinas. Los avances en las tecnologías de comunicación e informática, mayor comprensión sobre el origen y dinámica del universo, son logros de esta civilización. Sin embargo el avance científico y sus aplicaciones no han sido cuidadosos con la preservación del entorno natural. Cada vez existen más amenazas de desastres tecnológicos incontrolables.

Nadie duda de la necesidad de incrementar el saber científico. Para América Latina es crucial. Sin embargo también se levanta con fuerza la necesidad de discutir sobre los usos de las aplicaciones científicas. En la medida que el ciudadano común se incorpore a este debate, la utilización del conocimiento derivará en aplicaciones más satisfactorias para los hombres. Una tarea de la democratización de la sociedad, es incorporar estos temas en el debate. En países como los nuestros, se presenta una buena oportunidad de discutir sobre estos temas, toda vez que el rol de la ciencia y tecnología ha sido tradicionalmente ignorado o subestimado. Sería muchos más adecuado hacer que la ciudadanía

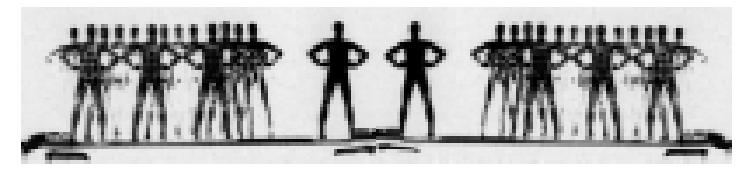

fevereiro, 2000 
forme parte de esta discusión. El necesario establecimiento de estructuras científicotecnológicas y los recursos que esto requiere serían mucho mejor comprendidos si la sociedad está comprometida con el esfuerzo.

La gestión de los gobiernos en América Latina también debería orientarse, en la elaboración de políticas científicas, a considerar la opinión de la ciudadadanía al respecto. El desafío hoy se plantea de como aprovechar el desarrollo científico en tecnologías más limpias y menos perturbadoras del medio natural. Esto exige una base científica sólida, con utilización más eficaz de los recursos y con formas de producción más seguras.

No sólo se hace necesario desarrollar las ciencias naturales, también son de interés las ciencias sociales. Sus estudios y conclusiones nos permitirán comprender más adecuadamente nuestra cultura. El análisis social es un componente indispensable en la formulación de políticas públicas y en las repercusiones que tienen en las comunidades de diferente cultura el impacto de las aplicaciones científico-tecnológicas.

El quehacer científico en el ámbito regional debe dar saltos cualitativos $y$ cuantitativos. En este sentido y a manera de propuesta se podrían plantear los siguientes aspectos, sin que esto signifique dar una respuesta global a este tema.

Aumentar la formación de científicos Los recursos humanos para la actividad científica en la región son claramente insuficientes. Las universidades $e$ institutos de investigación tienen la tarea de generar estrategias que permitan incrementar sustancialmente la capacidad científica de la región. Los aportes públicos deberán ser más generosos, sin olvidar el creciente interés del sector privado en incorporarse a este desafío. Los gobiernos deberían considerar en sus estrategias, incorporar al sector privado para

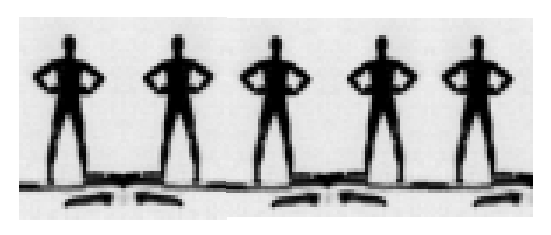
que hagan inversiones en ciencia y tecnología.
Formación y desarrollo de institutos científico-tecnológicos

Las demandas de la región deben ser satisfechas con la infraestructura adecuada. Esto también contribuye a la integración cuando estos institutos se definen en una marco de necesidades regionales o subregionales para el estudio de aspectos específicos. Un ejemplo de esto lo están dando las investigaciones sobre la Amazonia que llevan adelante universidades de dicha región. Estudios sobre desertificación, manejo de cuencas hídricas, recursos marinos etc., bien valen el esfuerzo de convergencia regional de recursos para su estudio.

Líneas de investigación regional Asociado al punto anterior, se debe mencionar la necesidad de afianzar el establecimiento de estudios regionales en las áreas más demandantes de información científica. Esto, junto con potenciar nuestros cuadros científicos, contribuye a dar más identidad y compromiso con la realidad diversa que tenemos. Ya mencionábamos al inicio de esta intervención, como los países desarrollados invierten la casi totalidad de sus recursos para buscar las explicaciones que les demandan sus problemas y urgencias. América Latina también debe ser capaz, con sus recursos intelectuales y materiales, de potenciar el conocimiento de nuestras necesidades para discurrir la forma de resolverlas.

\section{Conclusión}

A la Ciencia y Tecnología les corresponde jugar un papel destacado en el logro de una integración regional, permitiendo un crecimiento económico de la región sobre la base de un desarrollo sustentable, compartiendo nuestras potencialidades, aumentando y mejorando nuestros cuadros académicos y profesionales de investigación, postgrado, de movilidad social, académica y estudiantil y manteniendo nuestra identidad regional. 